\title{
The Role of Macrophages in Kidney Fibrosis
}

\author{
Xiaoling Wang, ${ }^{1,2}$, Jianwei Chen ${ }^{3}$, Jun $\mathrm{Xu}^{4}$, Jun Xie ${ }^{1 * t}$, David C. H. Harris ${ }^{3 \dagger}$ and \\ Guoping Zheng ${ }^{3 *+}$
}

${ }^{1}$ Shanxi Key Laboratory of Birth Defect and Cell Regeneration, Shanxi Medical University, Taiyuan, China, ${ }^{2}$ Clinical Laboratory, Shanxi Academy of Traditional Chinese Medicine, Taiyuan, China, ${ }^{3}$ Centre for Transplant and Renal Research, Westmead Institute for Medical Research, The University of Sydney, Sydney, NSW, Australia, ${ }^{4}$ Department of General Surgery, First Hospital of Shanxi Medical University, Taiyuan, China

The phenotypic heterogeneity and functional diversity of macrophages confer on them complexed roles in the development and progression of kidney diseases. After kidney injury, bone marrow-derived monocytes are rapidly recruited to the glomerulus and tubulointerstitium. They are activated and differentiated on site into pro-inflammatory M1 macrophages, which initiate Th1-type adaptive immune responses and damage normal tissues. In contrast, anti-inflammatory M2 macrophages induce Th2-type immune responses, secrete large amounts of TGF- $\beta$ and anti-inflammatory cytokines, transform into $\alpha S M A+$ myofibroblasts in injured kidney, inhibit immune responses, and promote wound healing and tissue fibrosis. Previous studies on the role of macrophages in kidney fibrosis were mainly focused on inflammation-associated injury and injury repair. Apart from macrophage-secreted profibrotic cytokines, such as TGF- $\beta$, evidence for a direct contribution of macrophages to kidney fibrosis is lacking. However, under inflammatory conditions, Wnt ligands are derived mainly from macrophages and Wnt signaling is central in the network of multiple profibrotic pathways. Largely underinvestigated are the direct contribution of macrophages to profibrotic signaling pathways, macrophage phenotypic heterogeneity and functional diversity in relation to kidney fibrosis, and on their cross-talk with other cells in profibrotic signaling networks that cause fibrosis. Here we aim to provide an overview on the roles of macrophage phenotypic and functional diversity in their contribution to pro-fibrotic signaling pathways, and on the therapeutic potential of targeting macrophages for the treatment of kidney fibrosis.

Keywords: macrophages, fibrosis, signaling pathways, TGF- $\beta$, Wnt Renal and Epithelial Physiology, a section of the journal Frontiers in Physiology

Received: 06 May 2021 Accepted: 07 June 2021 Published: 06 August 2021

Citation:

Wang X, Chen J, Xu J, Xie J, Harris DCH and Zheng $G$ (2021) The

Role of Macrophages in Kidney Fibrosis. Front. Physiol. 12:705838. doi: $10.3389 /$ fphys.2021.705838

\section{INTRODUCTION}

Kidney fibrosis is an inevitable outcome of all progressive chronic kidney diseases (CKD), including hypertensive, diabetic, and vascular nephropathy. Chronic inflammation is a direct cause of kidney injury. Chronic inflammation leads to excessive kidney repair and consequent kidney fibrosis and thereby failure of kidney function. Macrophages have long been known to be master players in inflammatory kidney diseases and to be associated with the development of kidney fibrosis in CKD. However, evidence for a direct contribution of macrophages to kidney fibrosis is lacking. Here we summarize the biological and pathological functions of macrophages polarized during the course 
of disease progression and their role in the development of kidney fibrosis in CKD, in particular, their contribution to profibrotic signaling networks.

\section{MACROPHAGE AS A MASTER PLAYER IN KIDNEY FIBROSIS}

Macrophages are an important part of the mononuclear phagocyte system comprising monocytes, macrophages, and dendritic cells (Viehmann et al., 2018). Mouse F4/80 or human epidermal growth factor module-containing mucin-like receptor 1 (EMR1) are considered to be signature markers of macrophage (Khazen et al., 2005). Macrophages are primarily responsible for pathogen clearance and the repair of injured tissues (Rosenberger and Finlay, 2003; Das et al., 2015). They are multifunctional cells with great phenotypic plasticity serving at the frontier of innate immune defenses. Kidney macrophages include long-lived tissueresident macrophages and macrophages derived from circulating monocytes of bone marrow origin (Tang et al., 2019). With functional diversity depending on the local microenvironment, macrophages play a critical role in inflammatory kidney disease (Wang and Harris, 2011).

Kidney fibrosis develops in a milieu of inflammatory cell infiltration, mesenchymal cell proliferation and activation, and progressive deposition of extracellular matrix (ECM), leading to scar formation (fibrosis) that destroys the parenchymal structure of kidney and causes progressive loss of kidney function. Observations from human CKD and experimental CKD models have shown that tubulointerstitial fibrosis is an essential feature of chronic kidney failure, and the degree of macrophage infiltration is directly associated with the severity of fibrosis (Yu et al., 2010). Accumulation of kidney macrophages correlates with severity of kidney injury and kidney fibrosis in human and experimental diabetic nephropathy (Chow et al., 2004) and also in other classically non-inflammatory kidney diseases. The infiltration of monocytes expressing chemokine (C-C motif) receptor 2 (CCR2) leads to kidney inflammation and fibrosis in murine chronic obstructive nephropathy (Braga et al., 2018). Kidney macrophage numbers and chemokine (C-C motif) ligand 2 (CCL2) levels correlate significantly with the progression of interstitial fibrosis in human CKD (Eardley et al., 2008). Moreover, selective depletion of macrophages reduces kidney fibrosis (Furuta et al., 1993). These studies support a role for macrophages in genesis and progression of kidney inflammation and fibrosis.

In $\mathrm{CKD}$, macrophages polarize to various phenotypes in response to complex microenvironmental stimuli in diseased kidneys. Macrophages of different phenotypes secrete a variety of growth factors, cytokines, proteins, and enzymes which contribute to or mitigate fibrosis (Eddy and Neilson, 2006). Macrophages produce profibrotic mediators including TGF- $\beta$, Wingless and Int-1 (Wnt), platelet-derived growth factor (PDGF), tumor necrosis factor $\alpha$ (TNF- $\alpha$ ), hepatocyte growth factor (HGF), connective tissue growth factor (CTGF), angiotensin converting enzyme (ACE), angiotensin I (Ang I) and II (Ang II), plasminogen activators, plasminogen activator inhibitor-1 (PAI-1), tissue inhibitor of metalloproteinases
(TIMP), collagen, fibronectin, thrombospondin, coagulation factors, reactive oxygen species, and endothelin. They can also produce mediators that protect against kidney fibrosis including collagenases, matrix metalloproteinase 12 (MMP-12), nitric oxide, and bone morphogenic protein-7 (BMP-7) (Eddy, 2011). Macrophages of various phenotypes are therefore responsible for several key processes in progressive fibro-inflammatory kidney disease, including initiation of inflammatory damage, resolution of inflammation, phagocytotic clearance of debris after inflammation, tissue repair, remodeling of fibrotic tissue, and excessive repair leading to irreversible kidney fibrosis. Thus, macrophages play very complex roles in kidney fibrosis (Ricardo et al., 2008; Shen et al., 2014; Table 1).

\section{MACROPHAGE CONTRIBUTIONS TO KIDNEY FIBROSIS VIA INFLAMMATION}

Inflammation, starting from recruitment and activation of macrophages, is considered to be a key factor behind fibrotic diseases (Cao et al., 2015). Macrophages are rapidly recruited to the glomerulus or tubulointerstitium to initiate innate immune responses and play important defensive as well as destructive roles in kidney injury. Ongoing kidney damage can cause continuing macrophage infiltration in a vicious cycle that leads to destruction of the normal kidney tissue structure and irreversible tissue fibrosis. Although it is widely believed that glomerular and interstitial macrophages are closely associated with development of kidney fibrosis, they also play beneficial roles in stromal remodeling during tissue repair (Ricardo et al., 2008; Alikhan and Ricardo, 2013). It is important to understand the complex roles of macrophages in kidney inflammation and fibrosis.

\section{Inflammatory Role of M1 Macrophages}

The ability of macrophages to play complex roles in kidney diseases is explained by their phenotypic heterogeneity and functional diversity (Anders and Ryu, 2011). Macrophages are activated and differentiated under specific microenvironmental conditions into two broad phenotypes, namely classically activated macrophages (CAM or M1) and alternatively activated macrophages (AAM or M2) (Figure 1). However, the concept of M1 and M2 macrophage phenotypes was mostly derived from in vitro observations of cultured macrophages. Such distinct M1 and M2 macrophage phenotypes are not consistent with in vivo observations, where M1 and M2 markers can co-exist on same macrophage (Wang et al., 2014). We use the terms of M1 and M2 macrophage phenotypes in this review for the convenience in citing respective studies and for description of functionally different macrophages. The existence of such heterogeneous phenotypes is explained by the cellular plasticity of circulating monocytes and macrophages in response to different stimuli. There is compelling evidence that the major factor determining kidney injury versus tissue restoration is the activation state of macrophages within local tissues rather than the degree of macrophage infiltration (Ricardo et al., 2008).

Circulating monocytes are recruited by cytokines and chemoattractants within the pathogenic microenvironment of 
TABLE 1 | Macrophage phenotypes, stimuli, Secreted products, and functions.

\begin{tabular}{|c|c|c|c|}
\hline $\begin{array}{l}\text { Macrophage } \\
\text { phenotypes }\end{array}$ & Stimuli & Secreted products & Phenotypic function \\
\hline M1 & $\begin{array}{l}\text { LPS (Kalish et al., 2015), TNF- } \alpha \\
\text { (Venturin et al., 2016), IFN- } \gamma \text { (Lee et al., } \\
\text { 2011), S100A9 (Tang et al., 2019), } \\
\text { IL-1 } \alpha \text { (Tang et al., 2019) }\end{array}$ & $\begin{array}{l}\text { IL-1 (Tang et al., 2019), IL-1ß (Wong et al., 2018), IL-6 } \\
\text { (Tang et al., 2019), IL-8 (Kadowaki et al., 2009), IL-12 } \\
\text { (Tang et al., 2019), IL-17A (Wong et al., 2018), IL-23 } \\
\text { (Tang et al., 2019), TNF- } \alpha \text { (Inoue, 2017), iNOS (Inoue, } \\
\text { 2017), MMP-12 (Tang et al., 2019), CCL-2 (Wong et al., } \\
\text { 2018), CCL-3 (Meng et al., 2015), CCL-5 (Meng et al., } \\
\text { 2015), CXCL1 (Meng et al., 2015), CXCL2 (Meng et al., } \\
\text { 2015), CXCL10 (Meng et al., 2015), ICAM-1 (Wong } \\
\text { et al., 2018), Wnt5a (Blumenthal et al., 2006) RAS } \\
\text { (Ulrich et al., 2011) }\end{array}$ & $\begin{array}{l}\text { Pro-inflammatory and TH1-like immune } \\
\text { response (Tang et al., 2019) }\end{array}$ \\
\hline $\mathrm{M} 2 \mathrm{a}$ & $\begin{array}{l}\text { IL-4 (Zhang et al., 2017; Tang et al., } \\
\text { 2019), IL-13 (Zhang et al., 2017; Tang } \\
\text { et al., 2019) }\end{array}$ & $\begin{array}{l}\text { Mannose and scavenger receptor (Anders and Ryu, } \\
\text { 2011), decoy IL-1R11 (Anders and Ryu, 2011), FIZZ1 } \\
\text { (Anders and Ryu, 2011), YM-1 (Anders and Ryu, 2011), } \\
\text { IL-10 (Lu et al., 2013), TGF- } \beta \text { (Lu et al., 2013), Wnt1, } \\
\text { Wnt3a (Cosin-Roger et al., 2019), Wnt7b (Lin et al., } \\
\text { 2010) CCL13 (Meng et al., 2015), CCL14 (Meng et al., } \\
\text { 2015), CCL17 (Meng et al., 2015), CCL18 (Meng et al., } \\
\text { 2015), CCL22 (Meng et al., 2015), CCL23, CCL24 } \\
\text { (Meng et al., 2015), CCL26 (Meng et al., 2015), MMP-9 } \\
\text { (Meng et al., 2015), MMP-12 (Meng et al., 2015), IGF-1 } \\
\text { (Meng et al., 2015), arginase } 1 \text { (Tseng et al., 2020), } \\
\text { Fibronectin (Tseng et al., 2020) }\end{array}$ & $\begin{array}{l}\text { Anti-inflammatory TH2-like immune } \\
\text { response (Tang et al., 2019), wound } \\
\text { healing and tissue fibrosis (Tang et al., } \\
\text { 2019), inhibition of T-cell proliferation } \\
\text { (Lu et al., 2013) }\end{array}$ \\
\hline M2b & $\begin{array}{l}\text { Immune complexes (IgG4) (Bianchini } \\
\text { et al., 2019; Tang et al., 2019), } \\
\text { TLR/IL-1R ligand (Tang et al., 2019), } \\
\text { IL-1R (Lisi et al., 2014), IgG Fc receptor } \\
\text { ligands (Lisi et al., 2014), CD40 (Lisi } \\
\text { et al., 2014), IL-6 (Philipp et al., 2018) }\end{array}$ & $\begin{array}{l}\text { IL-1 (Anders and Ryu, 2011), IL-6 (Anders and Ryu, } \\
\text { 2011), TNF- } \alpha \text { (Anders and Ryu, 2011), MHCllhi (Anders } \\
\text { and Ryu, 2011), IL-10hi (Anders and Ryu, 2011), } \\
\text { IL-12lo (Anders and Ryu, 2011), IL-1 } \beta \text { (Wang et al., } \\
\text { 2019), MCP-1 (Chen et al., 2013), iNOS (Chen et al., } \\
\text { 2013) }\end{array}$ & $\begin{array}{l}\text { Immunoregulation (Tang et al., 2019), } \\
\text { Th2 activation (Meng et al., 2015) }\end{array}$ \\
\hline M2c & $\begin{array}{l}\text { IL-10 (Tang et al., 2019), TGF- } \beta \text { (Tang } \\
\text { et al., 2019), glucocorticoids (Tang } \\
\text { et al., 2019) }\end{array}$ & $\begin{array}{l}\text { IL-10 (Anders and Ryu, 2011), TGF- } \beta \text { (Anders and Ryu, } \\
\text { 2011), mannose receptor (Anders and Ryu, 2011), } \\
\text { B7-H4 (Lu et al., 2013), arginase } 1 \text { (Meng et al., 2015) }\end{array}$ & $\begin{array}{l}\text { Immunosuppression (Tang et al., 2019), } \\
\text { matrix remodeling and tissue repair } \\
\text { (Tang et al., 2019), inhibition of T-cell } \\
\text { proliferation (Lu et al., 2013), induction } \\
\text { of Tregs (Lu et al., 2013) }\end{array}$ \\
\hline
\end{tabular}

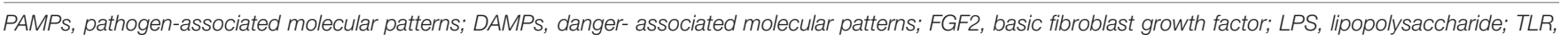

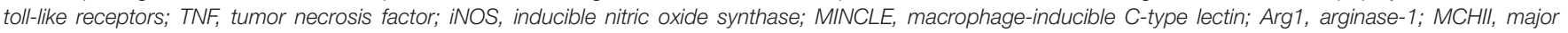

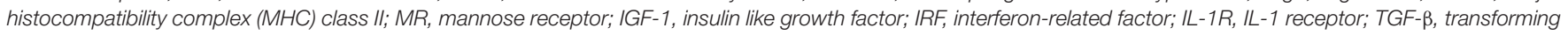
growth factor- $\beta$; Wnt, Wingless and Int-1; RAS, renin angiotensin system.

diseased kidneys. They adhere to activated endothelial surfaces, infiltrate into interstitial and/or glomerular compartments, and differentiate into pro-inflammatory M1 macrophages (Tang et al., 2019). M1 macrophages can be polarized by pathogen-related molecular patterns (PAMPs) such as lipopolysaccharides (LPS), alarmins such as S100A9 and IL- $1 \alpha$, and pro-inflammatory cytokines such as tumor necrosis factor $\alpha$ (TNF- $\alpha$ ) (Kalish et al., 2015; Venturin et al., 2016). Polarized M1 macrophages highly express major histocompatibility complex (MHC) class II and co-stimulating molecule CD86 and initiate Th1 type adaptive immune responses, resulting in cytotoxicity and more effective killing of bacteria, intracellular pathogens and tumor cells (Lv et al., 2017; Tang et al., 2019). Concurrently, M1 macrophages secrete a series of pro-inflammatory factors (including IL-1, IL6, IL-12, TNF- $\alpha$ ), chemokines (such as IL-8), activated oxygen species, and nitric oxide (NO) which promote inflammation and damage of normal tissues (Inoue, 2017; Tang et al., 2019).

In the early stage of kidney ischemia-reperfusion injury (IRI) in rats, macrophages are M1 in phenotype and highly express iNOS (Huen and Cantley, 2015). Depletion of macrophages at this stage by liposome clodronate significantly attenuated kidney injury, accompanied with decreased expression of inflammatory and profibrotic cytokines (Ko et al., 2008). Similarly, miR-30c-5p agomir which directly inhibits Interferon regulatory factor 1 (IRF1) reduced kidney ischemic injury by reducing M1 macrophages and increasing of M2 macrophages, and by reducing inflammatory cytokine TNF- $\alpha$ and increasing anti-inflammatory cytokines IL-4 and IL-10 (Zhang et al., 2019; Guo et al., 2020). In contrast, transfusion of IFN- induced M1 macrophages following acute kidney IRI increased tubulointerstitial fibrosis and functional impairment (Lee et al., 2011).

Apart from inflammatory cytokines, activated macrophages also secrete matrix metalloproteinases (MMPs), including abundant MMP- $1,-3,-7,-9,-10,-12,-14$, and -25 with less abundant MMP-2, 3, 8, 10, 11, 12 (Huang et al., 2012). Those MMPs contribute not only to degradation of extracellular matrix, but also to inflammatory injury in kidney (Kunugi et al., 2011). Macrophage-derived MMP-9 has been shown to contribute to kidney fibrosis through induction 


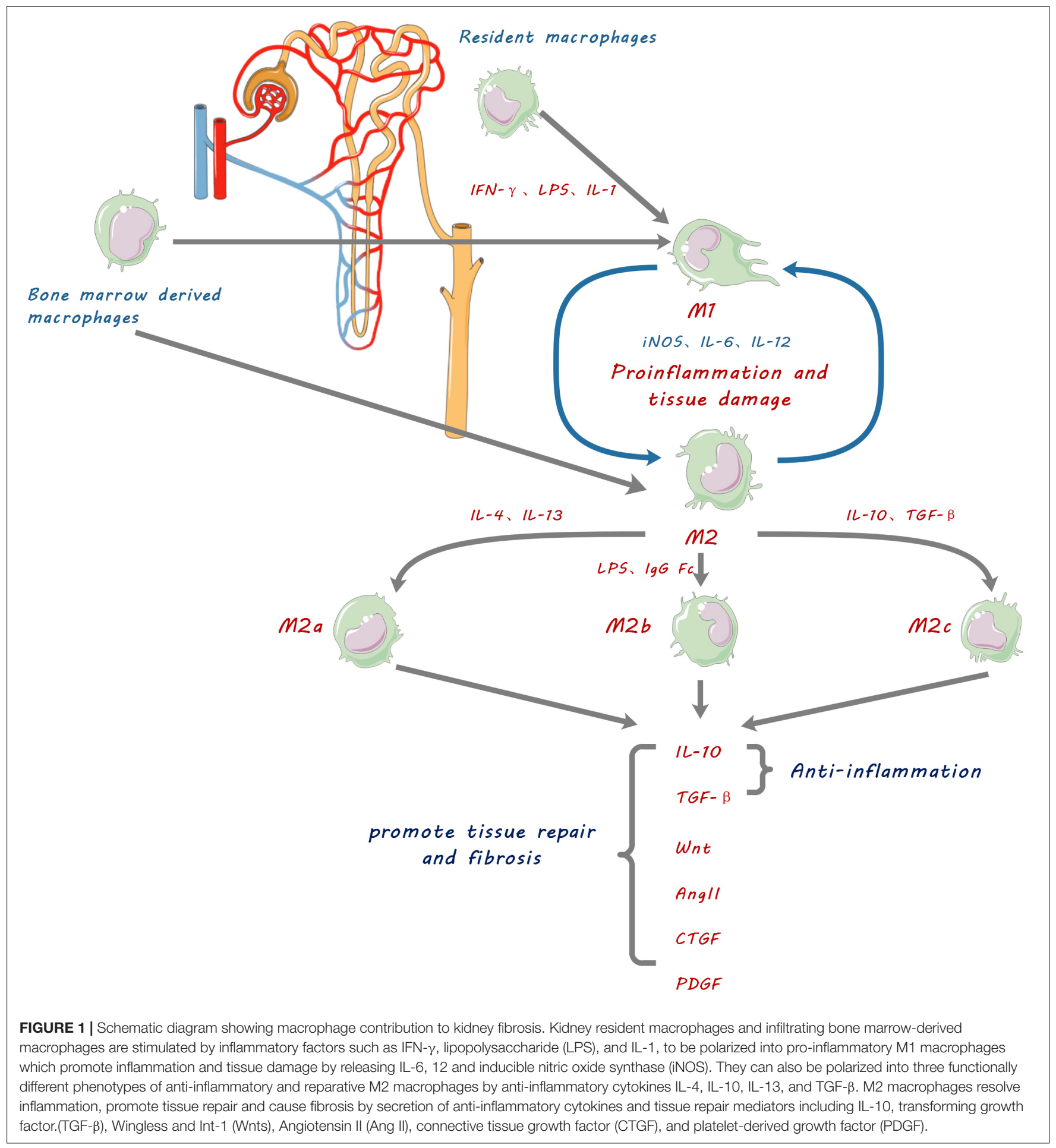

of profibrotic changes in tubular epithelial cells (Tan et al., 2010) and recruitment of macrophages via proteolytic activation of osteopontin (Tan et al., 2013). More importantly, MMPmediated proteolytic releasing and activation of TGF- $\beta$ bound to extracellular matrix (Karsdal et al., 2002) may directly contribute to kidney fibrosis and indirectly through induction of profibrotic M2 macrophages.
In addition to promotion of inflammation and tissue damage, pro-inflammatory M1 macrophages were found also to be capable of switching to anti-inflammatory and reparative M2 macrophages (Arnold et al., 2007). Thus, the classification of M1 and M2 macrophage phenotypes may well represent but oversimplify the plastic functional status of macrophages at different stages of disease progression. 


\section{Anti-inflammatory and Pro-fibrotic Roles of M2 Macrophages}

Alternatively activated macrophages, M2 macrophages, can be defined from in vitro experiments into three functional subtypes according to their activation stimuli and functions: M2a, M2b, and M2c (Tang et al., 2019; Figure 1). M2a macrophages are typically induced by IL-4 and IL-13 (Zhang et al., 2017); M2b macrophages are induced by immune complexes, LPS, IgG Fc receptor ligands, and CD40 (Lisi et al., 2014); M2c macrophages are induced by IL-10 and TGF- $\beta$ or glucocorticoids (Kim et al., 2015). Those phenotypic definitions of anti-inflammatory M2 macrophages are used for the convenience in description of their respective functions.

The subtypes of M2 macrophages are thought to suppress immune responses and promote tissue repair, but with different and sometimes controversial functions (Mantovani et al., 2004). M2a macrophages, highly express the marker arginase 1 (Arg1), produce a large amounts of anti-inflammatory IL-10 and IL-1 receptor antagonist (IL-1ra), and inhibit secretion of proinflammatory cytokines (IL-12, IL-1, TNF- $\alpha$ ) and production of NO, thereby exerting anti-inflammatory and immunosuppressive functions. M2b macrophages specifically up-regulate IL-10 and down-regulate IL-12, and induce T cells to secrete IL-4, which in turn promotes $\mathrm{B}$ cells to produce antibodies, and induce antiinflammatory Th2 immune responses. M2c macrophages secrete large amounts of IL-10 and TGF- $\beta$, suppress inflammatory immune responses, and promote wound healing and tissue fibrosis (Tang et al., 2017, 2019). Supporting evidence includes that reduced infiltration of macrophages (mainly M2) in murine models of kidney disease can prevent progressive interstitial collagen deposition and inhibit kidney fibrosis (Kim et al., 2015). Furthermore, the adoptive transfer of M2c macrophages rather than M1 macrophages reversed the beneficial effects of macrophage depletion in kidney fibrosis (Tang et al., 2019). In the unilateral ureteral obstruction (UUO) model, depletion of macrophages from day 4 significantly reduced kidney fibrosis, while the adoptive transfer of M2 macrophages promoted the accumulation of $\alpha \mathrm{SMA}+$ cells and kidney fibrosis (Shen et al., 2014). In a rat model of anti-glomerular basement membrane disease, inhibition of M2 macrophage infiltration by inhibitor of the macrophage-specific c-fms receptor at days 1435 resulted in a significant reduction in both glomerular sclerosis and interstitial fibrosis (Han et al., 2013). Consistent with findings from experimental animal models, the number of M2 macrophages expressing CD206 and/or CD163 is associated with kidney interstitial fibrosis and tubular atrophy in human kidney diseases such as diabetic nephropathy, IgA nephropathy, and in kidney transplants (Wu et al., 2020). Together these findings indicate that M2 macrophage polarization and infiltration can promote kidney fibrosis and progression of kidney disease. However, in acute or non-persistent kidney injuries such as acute tubular necrosis (ATN), M2 macrophages were mainly anti-inflammatory and promoted epithelial healing and rapid regeneration of intact tubules (Anders and Ryu, 2011).

M2 macrophages were thought to promote kidney fibrosis via secretion of TGF- $\beta 1$ which is well-known to cause fibrosis; larger quantities of TGF- $\beta 1$ were detected in M2 macrophages than in myofibroblasts in the UUO model (Shen et al., 2014). However, macrophage-specific deletion of TGF- $\beta 1$ failed to prevent renal fibrosis after severe ischemia-reperfusion or obstructive injury (Huen et al., 2013). In contrast, selective deletion of TGF- $\beta$ receptor II (T $\beta$ RII) in monocytes/macrophages promoted kidney fibrosis by enhancing renal macrophage infiltration (Chung et al., 2018). These controversial findings suggested that it would be too simplistic to conclude or disprove profibrotic roles of macrophage TGF- $\beta 1$ by selective depletion of either TGF- $\beta 1$ or its receptor (T $\beta$ RII) alone, given that TGF- $\beta 1$ is also the most potent anti-inflammatory factor secreted by M2 macrophages (Ricardo et al., 2008), and inflammation is unarguably the initial cause of kidney fibrosis (Tang et al., 2019). We found that by alteration of TGF- $\beta 1$ signaling in bone marrowderived macrophages via shifting $\beta$-catenin binding from TCF to Foxo1 using $\beta$-catenin/TCF inhibitor ICG-001, the antiinflammatory function of TGF- $\beta 1$ was enhanced by increased production of anti-inflammatory IL-10 and reduced production of IL- 6 and TNF- $\alpha$ in the bone marrow-derived macrophages. Concurrently the pro-fibrotic effect of TGF- $\beta 1$ was abolished by significant reduction of GFP (+) F4/80 (+) $\alpha$-SMA (+) bone marrow-derived macrophages undergoing macrophagemyofibroblast transformation (MMT) (Wang et al., 2017) and thereby kidney fibrosis was reduced in the murine model of unilateral ureteral obstruction (UUO) (Yang et al., 2019).

In addition to TGF- $\beta 1$, M2 macrophage polarization is also tightly regulated by the Wnt pathway. Wnt5a can enhance TGF- $\beta$-induced macrophage M2 polarization and the expression of Yes-associated protein (Yap)/transcriptional coactivator with PDZ-binding motif (Taz) to promote kidney fibrosis (Feng et al., 2018a). The Wnt ligand Wnt3a induces the polarization of M2 macrophages by enhancing IL- 4 or TGF- $\beta 1$ (Feng et al., 2018b). Conditional deletion of Wnt3a in bone marrow cells lessens the accumulation of macrophages and the polarization of M2, and reduces kidney fibrosis in the murine UUO model (Feng et al., 2018b).

\section{Bone Marrow Macrophage Contribution to Kidney Fibrosis}

Bone marrow-derived monocytes are recruited to the kidney after injury. They constitute a large proportion of interstitial infiltrating macrophages (Tang et al., 2019) and play a major role in progression of kidney fibrosis as they polarize to macrophages of various phenotypes (Conway et al., 2020). Bone marrow-derived macrophages can differentiate into $\alpha$-SMA+ myofibroblasts in injured kidney, via MMT (Ikezumi et al., 2015; Wang et al., 2017). Flow cytometric analysis found that most CD45+ leukocytes isolated from obstructed kidneys expressed both collagen I and $\alpha$-SMA (Chen et al., 2011). The $\mathrm{CD} 45+$ cells in these fibrotic kidneys are infiltrating monocytes derived from bone marrow. They have undergone MMT and transdifferentiated into collagen-producing myofibroblasts within the microenvironment of the damaged kidney, driven by TGF- $\beta 1$ (Nikolic-Paterson et al., 2014) secreted by M2 macrophages (Shen et al., 2014). In vitro TGF- $\beta 1$ drove 
transdifferentiation of cultured macrophages into collagensecreting $\alpha$-SMA + myofibroblasts (Pilling and Gomer, 2012). Cells expressing macrophage marker CD68 and myofibroblast marker $\alpha$-SMA + have been identified in the kidney of patients with active fibrosis (Meng et al., 2016b). Nikolic-Paterson et al. (2014) found evidence of MMT in human kidney disease with active fibrosis using confocal microscopy, and showed that the severity of kidney fibrosis correlated with the number of MMT cells co-expressing $\alpha$-SMA and CD68. In addition to TGF- $\beta 1$, chemokine receptor CXCR6 contributes to recruitment of bone marrow-derived fibroblast precursors (Xia et al., 2014), while IL-4 and IL-13 activated Jak3/STAT6 signaling stimulates bone marrow-derived fibroblast MMT in the UUO model of kidney fibrosis (Yan et al., 2015; Liang et al., 2017).

The contribution of bone marrow-derived macrophages to kidney fibrosis is also supported by the observation that down-regulation of CCR2 expression reduced recruitment and activation of myeloid derived macrophages and alleviated kidney fibrosis in UUO model (Jiang et al., 2019). Production of chemokine CXCL16 by kidney tubular epithelial cells is necessary for recruitment of myeloid derived CD $45+$ col I $+\alpha$-SMA + cells and development of kidney fibrosis in UUO model (Chen et al., 2011; Nikolic-Paterson et al., 2014).

\section{MACROPHAGE CONTRIBUTION TO PROFIBROTIC SIGNALING PATHWAYS}

Kidney fibrosis is the direct result of activation of fibroblasts and accumulation of myofibroblasts, driven by multiple profibrotic signaling pathways (Kuppe et al., 2021). Profibrotic changes in other cells, including mesenchymal transition of tubular epithelial cells (EMT) (Zheng et al., 2009; Tan et al., 2010; Qiao et al., 2018; Yang et al., 2020; Rao et al., 2021) and endothelial cells (EndoMT) (Zeisberg et al., 2008; Li et al., 2010; LeBleu et al., 2013; Zhao et al., 2016), also contribute to the activation of fibroblasts and kidney fibrosis, but may not directly transform into myofibroblasts (Kuppe et al., 2021).

\section{Wnt/ $\beta$-CATENIN SIGNALING PATHWAY}

The $\mathrm{Wnt} / \beta$-catenin signaling pathway is activated in various kidney diseases, contributing to the development and progression of kidney fibrosis (Zhou et al., 2020). Wnt/ $\beta$-catenin signaling is an evolutionarily conserved pathway involved in embryonic development, tissue homeostasis, and organ injury repair (Ng et al., 2019; Perugorria et al., 2019). Wnt ligands are a large family of secreted glycoproteins and fundamentally indispensable for transduction of the Wnt signaling pathway (Nie et al., 2020).

$\mathrm{Wnt} / \beta$-catenin signaling in kidney disease is versatile; transient activation of $\mathrm{Wnt} / \beta$-catenin signaling induces repair and regeneration during acute kidney injury, but sustained (uncontrolled) Wnt/ $\beta$-catenin activation promotes kidney fibrosis (Schunk et al., 2021). Lin et al. (2010) found that

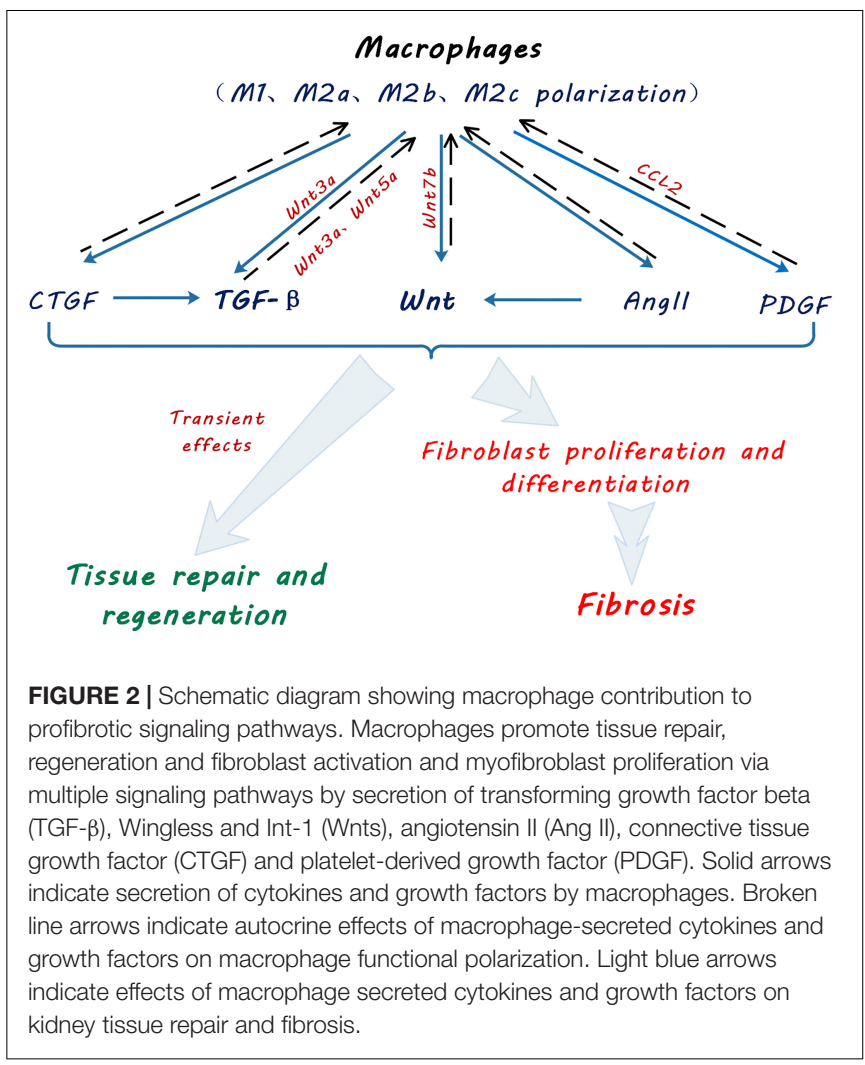

Wnt7b secreted by macrophages facilitates kidney regeneration through directing epithelial cell-cycle progression and basement membrane repair; kidney injury repair was substantially retarded after macrophage specific deletion of Wnt7b.

In kidney, Wnt5a promotes fibrosis by stimulating Yap/Tazmediated macrophage polarization in both UUO and IRI models (Feng et al., 2018a). Wnt3a can also promote M2 macrophage polarization induced by IL-4 or TGF- $\beta 1$, following $\mathrm{Wnt} / \beta$-catenin signaling activation, and in turn accelerate macrophage proliferation and accumulation, giving rise to kidney fibrosis (Cosin-Roger et al., 2019; Figure 2).

Studies of fibrosis in other organs also demonstrated macrophage contribution to the $\mathrm{Wnt} / \beta$-catenin pathway. After myocardial infarction in mice, macrophages within the area of infarction exhibited an increase in expression of non-canonical Wnt ligands Wnt5a and Wnt11 (Palevski et al., 2017). The activated $\mathrm{Wnt} / \beta$-catenin signal promoted cardiac fibrosis by inducing the transition of endothelial cells and epicardial cells to a mesenchymal state, fibroblast differentiation into myofibroblasts and collagen production (Palevski et al., 2017). In a murine model of intestinal fibrosis, CD16+ macrophages expressed high levels of Wnt6, inducing intestinal fibrosis (Salvador et al., 2018). M2 macrophage release of Wnt7a promoted myofibroblast differentiation of lung resident mesenchymal stem cells, leading to lung fibrosis (Hou et al., 2018). 


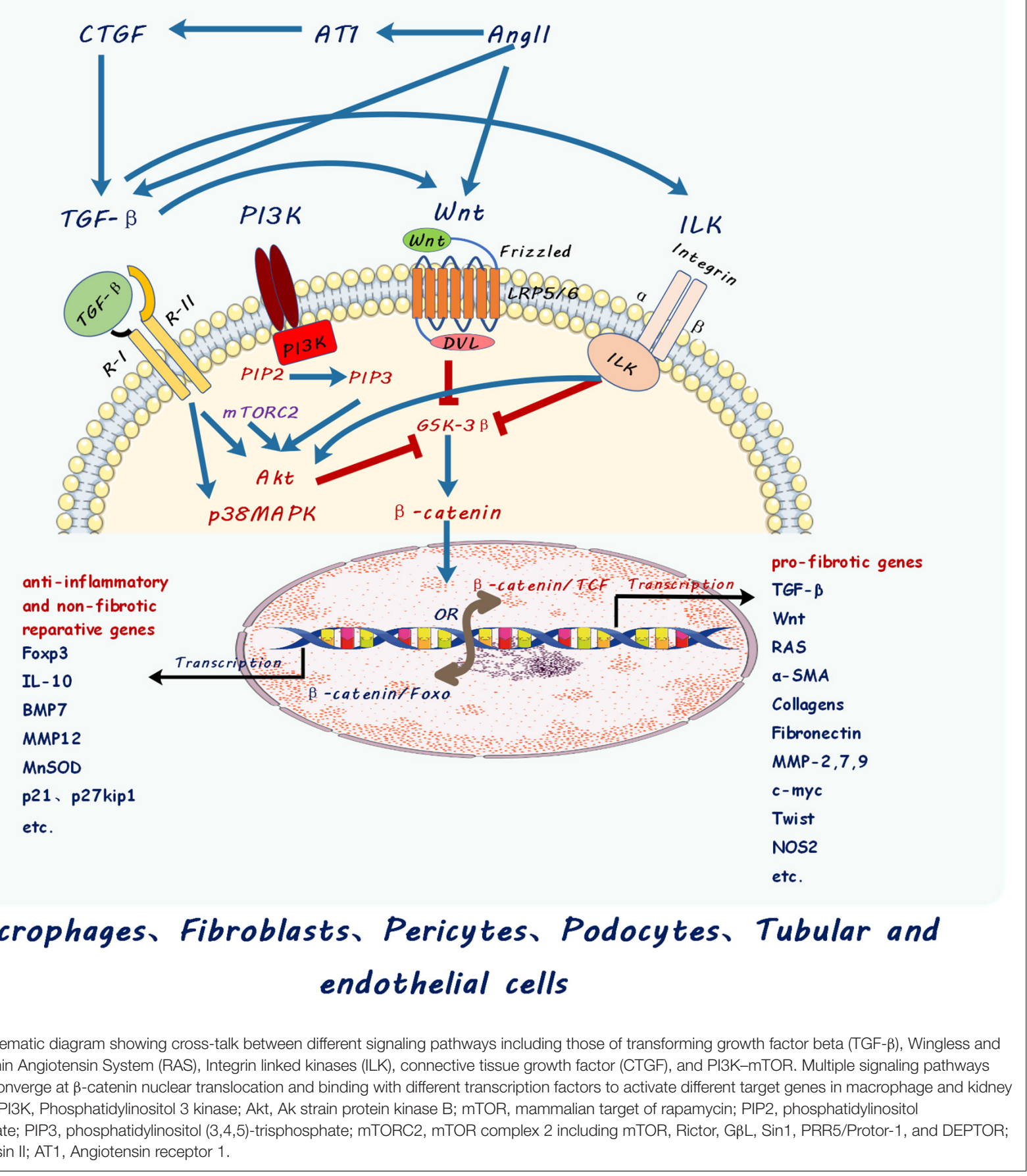

\section{TGF- $\beta$ SIGNALING PATHWAY}

TGF- $\beta$ is a well-known inducer of kidney fibrosis. While secretion of anti-inflammatory TGF- $\beta$ by M2 macrophages contributes to resolution of inflammation, it also mediates kidney injury repair and causes kidney fibrosis when in excess. The mechanism by which macrophages promote kidney fibrosis through the TGF$\beta$ signaling has been extensively investigated. M1 macrophages can be reprogrammed into alternately activated M2 macrophages by anti-inflammatory cytokine stimulation (IL-10 or colonystimulating factor 1) or upon their phagocytotic ingestion of apoptotic cells. M2 macrophages promote and coordinate the regeneration of kidney tubular cells and maintain the integrity of the kidney tubules after injury (Rogers et al., 2014). During tissue repair, M2b and M2c macrophages are mainly responsible for immunosuppression, matrix remodeling and wound healing once tissue damage has been resolved (Tang et al., 2019). In contrast, uncontrolled kidney inflammation triggers M2a 
macrophage polarization in the injured kidney through IL4 and IL-13, promoting increased TGF- $\beta 1$ production and kidney fibrosis (Pan et al., 2015). M2 macrophages exert antiinflammatory effects and promote kidney fibrosis through tissue repair by producing a large amount of TGF- $\beta 1$ in the UUO model (Eddy, 2005).

\section{RENIN-ANGIOTENSIN SYSTEM (RAS), PDGF AND CTGF SIGNALING PATHWAYS}

In addition to Wnt and TGF- $\beta$, macrophages are also identified as a source of components of the renin-angiotensin system (RAS), including renin, angiotensin converting enzyme (ACE), Ang I and Ang II, AT1 and AT2 receptors (Okamura et al., 1999). The RAS is known to cause kidney fibrosis through Wnt/ $\beta$-catenin signaling (Miao et al., 2019; Figure 2). Other profibrotic mediators such as PDGF and CTGF were also found to be produced by macrophages (Cicha et al., 2005; Eitner et al., 2008).

\section{INTEGRIN/ILK AND NOTCH SIGNALING PATHWAYS}

Apart from direct secretion of pro-fibrotic mediators, macrophages produce matrix metalloproteinases (MMP), which not only contribute to tissue remodeling after injury, but also activate other pro-fibrotic signaling pathways such as Integrin/ILK (Zheng et al., 2009, 2016; Tan et al., 2010) and Notch (Zhao et al., 2016).

\section{ACTIVATION AND PROLIFERATION OF MYOFIBROBLASTS BY CROSSTALK BETWEEN PROFIBROTIC SIGNALING PATHWAYS}

Activation and proliferation of myofibroblasts is a central and complex event in development of kidney fibrosis. It involves multiple signaling pathways activated by profibrotic mediators from the fibro-inflammatory microenvironment of the injured kidney. Macrophages are unarguably a major source of those mediators (Table 1). A profibrotic signaling network including TGF- $\beta /$ Smad, Wnt $/ \beta$-catenin, the renin- angiotensin system (RAS) and Integrin /ILK pathways cross-talk and synchronize to promote kidney fibrosis (Figure 3).

$\mathrm{Wnt} / \beta$-catenin signaling is a key player in kidney fibrosis contributing to activation of fibroblasts into myofibroblasts and consequent excessive extracellular matrix production. Upon binding of Wnt ligands to its receptor Frizzled $(\mathrm{Fz})$ and transmembrane receptor LRP5/6, dishevelled $(\mathrm{dvl})$ protein in the cytoplasm is phosphorylated and activated to bind to Axin to antagonize GSK3 $\beta$, which prevents $\beta$-catenin signaling by degradation of cytosolic $\beta$-catenin via phosphorylation and ubiquitination machinery (Tan et al., 2014; Wang Y. et al.,
2018). Inhibition of GSK3$\beta$ by Wnt ligands results in $\beta$-catenin nucleus translocation followed by transcriptional activation of Wnt target genes when $\beta$-catenin complexes TCF/LEF, the transcription binding partners of $\beta$-catenin (Zhou et al., 2012; Guo et al., 2019). This canonical Wnt/ $\beta$-catenin signaling pathway activates a transcriptome of profibrotic inducers such as Snail/Slug, and fibrotic genes such as $\alpha$ smooth muscle actin $(\alpha-S M A)$, collagen, fibronectin and other extracellular matrix genes involved in fibroblast activation and extracellular matrix production. Importantly, $\mathrm{Wnt} / \beta$-catenin signaling is not acting alone during the development of kidney fibrosis.

TGF- $\beta$ released by M2 macrophage is also one of the most important contributors to kidney fibrosis. TGF- $\beta$ signals through both Smad-dependent and Smad-independent pathways. TGF- $\beta$ binds to TGF- $\beta$ receptor II which sequentially complexes with TGF- $\beta$ receptor I. TGF- $\beta$ receptor II binding to receptor I then leads to receptor I phosphorylation of $\mathrm{Smad} 2 / 3$ which translocate into the nucleus with co-Smad4 to activate profibrotic gene transcription in kidney myfibroblasts (Meng et al., 2016a). In addition to Smad-dependent signaling in activating profibrotic genes in myofibroblasts, TGF- $\beta$ also promotes $\beta$-catenin nuclear translocation through phosphorylation of $\beta$-catenin Tyr-654 and dephosphorylation of $\beta$-catenin Ser-37 and Thr-41. Furthermore, Smad-independent activation of Akt and p38 MAP kinase (Wang et al., 2011; Zhou et al., 2012; Tan et al., 2014) also subsequently inhibit GSK $3 \beta$, thereby promoting $\beta$-catenin nuclear translocation and activation of $\mathrm{Wnt} / \beta$-catenin signaling.

The renin-angiotensin system (RAS) is also known to cause hypertension and fibrosis in CKD (Floege, 2015). Macrophage secretion of RAS components [renin, angiotensin converting enzyme (ACE), Ang I and Ang II] promote synthesis and release of profibrotic factors TGF- $\beta$, CTGF, PDGF, ET1 (Wang M. et al., 2018; Zhou et al., 2020) and is a direct target of the $\mathrm{Wnt} / \beta$-catenin pathway, causing kidney injury, and fibrosis. Reciprocally, blockade of $\mathrm{Wnt} / \beta$-catenin by inhibition of $\beta$-catenin/TCF signaling also blocks RAS and consequent hypertension and kidney fibrosis in CKD (Floege, 2015).

Integrin/ILK are known to contribute to both glomerular and interstitial fibrosis in diseased kidneys (Liu, 2010; Zheng et al., 2016). The underlying mechanism for ILK in causing fibrotic signaling involves its direct or indirect (via activation of $\mathrm{Akt}$ ) inhibition of GSK3 $\beta$ in facilitating $\beta$-catenin nuclear translocation and activation of $\mathrm{Wnt} / \beta$-catenin signaling (Liu, 2010). We found that proximal tubular cell upregulation of ILK via the compensatory increase of $\alpha 3$ integrin worsened kidney fibrosis in the UUO model in proximal tubular specific E-cadherin knockout mice (Zheng et al., 2016). Importantly, ILK is downstream of TGF- $\beta$ mediation of both glomerular and tubulointerstitial fibrosis in kidneys (Li et al., 2009; Kang et al., 2010). Our study demonstrated that autophagy links TGF- $\beta /$ Smad signaling with $\beta$-catenin through the pY654-betacatenin/p-Smad2/ILK pathway (Pang et al., 2016).

mTOR activation has been identified in macrophages and myofibroblasts in kidney fibrosis (Chen et al., 2012). mTORC1 activation in podocytes led to the development of glomerular crescents contributing to fibrosis of glomeruli 
in both experimental and human glomerulonephritis (Mao et al., 2014). mTORC2 is activated by TGF- $\beta$ to transduce profibrotic signaling through mTOR activation of PI3K-Akt (Li et al., 2015) which subsequently inactivates GSK3 $\beta$ to facilitate $\beta$-catenin nuclear translocation and thereby activate $\beta$-catenin/TCF in the $\mathrm{Wnt} / \beta$-catenin pathway. Macrophage polarization has been shown to be controlled by the PI3KAkt-mTOR pathway; increased mTORC1 activity promoted M1 macrophage polarization and reduced M2 macrophage polarization (Weichhart et al., 2015). mTOR activation was observed in myofibroblasts and macrophages and inhibition of mTOR pathway by rapamycin ameliorated kidney fibrosis (Chen et al., 2012). Both TGF- $\beta$ and ILK activate PI3K-Akt and thus cross-talk with mTOR, whereas mTORC2 activation of PI3KAkt also links with the $\mathrm{Wnt} / \beta$-catenin pathway via PI3K-Akt inhibition of GSK3 $\beta$ (Ching and Hansel, 2010).

Together multiple signaling pathways (TGF- $\beta$, Wnt, ILK, RAS, mTOR, etc.) interact via activation of $\beta$-catenin in the initiation and progression of kidney fibrosis. The functional status of $\beta$-catenin determines the activity of these signaling pathways and the progression or regression of kidney fibrosis. Studies from us and others demonstrated the key role for $\beta$-catenin/TCF in mediating profibrotic signaling of multiple pathways (Liu, 2010; Qiao et al., 2018). Importantly, we found that shifting $\beta$-catenin binding from TCF toward Foxo in both macrophages and kidney tubular cells by inhibition of $\beta$-catenin/TCF redirected TGF$\beta$ signaling from pro-fibrotic to anti-inflammatory, protected against kidney fibrosis and promoted epithelial repair in UUO and IRI models (Qiao et al., 2018; Rao et al., 2019, 2021; Yang et al., 2019).

\section{TARGETING MACROPHAGES AS A TREATMENT FOR KIDNEY FIBROSIS}

Anti-inflammatory and reparative properties of macrophages (Lin et al., 2010; Urbina and Singla, 2014; Ratnayake et al., 2021) argue for their therapeutic application. We have shown that ex vivo programmed M2 macrophages protect against inflammation and kidney injury in experimental models of inflammatory renal disease (Wang et al., 2007; Cao et al., 2010, 2011). Jung et al. (2012) found that infusion of IL-10 overexpressing macrophages protected ischemia injury in an IRI model. Adoptive transfer of genetically modified macrophages expressing heme-oxygenase-1 (HO1) protected kidney function in mice with IRI (Ferenbach et al., 2010). Netrin-1-induced M2 macrophages suppressed inflammation and protected against kidney injury in IRI mice (Ranganathan et al., 2013).

However, the phenotypic instability of those M2 macrophages remains as a challenge (Cao et al., 2014). To overcome the hurdle of phenotypic instability, adenovirus vector NGAL (Neutrophil gelatinase-associated lipocalin-2) was used to stabilize phenotype of injected M2 macrophages which reduced inflammation and fibrosis in UUO model. While protection by antiinflammatory M2 macrophages has been reported increasingly, the profibrotic effects of M2 macrophages remain largely unaddressed as another hurdle for their therapeutic application; M2 macrophages secrete large amounts of TGF- $\beta$ which not only suppresses inflammation but also promotes kidney fibrosis (Kim et al., 2015).

Depletion of inflammatory M1 macrophages does not protect against kidney fibrosis, while depletion of anti-inflammatory and reparative M2 macrophages can reduce kidney fibrosis (Shen et al., 2014). Thus, although inflammation is an important driver of fibrosis, other non-inflammatory profibrotic pathways are activated by anti-inflammatory and tissue reparative cytokines from M2 macrophages such as TGF- $\beta$, Wnt, Ang II, CTGF, and PDGF. Moreover, the results of these macrophage depletion studies are consistent with the fact that M1 and M2 macrophages represent different and sometimes coexisting functional phenotypes of the same population. They polarize across their life span according to stimuli within the microenvironment in which they reside during the progression kidney diseases.

Opposing roles of phenotypically distinct macrophages suggested that targeting macrophages of different phenotypes may not be practical in developing therapeutic treatment for fibrotic diseases (Cao et al., 2014). More importantly, precise targeting of functionally different macrophages with opposing roles requires a better understanding of downstream signaling events and the diverse functions of multi-functional cytokines, such as TGF- $\beta 1$ (Qiao et al., 2018), which although profibrotic contributes to suppression of inflammation and to tissue repair in kidney (Tang et al., 2019).

Instead of targeting specific functional phenotypes of macrophages, targeting a central factor in multiple profibrotic signaling pathways in macrophages is likely to be a more effective strategy for treating kidney diseases. Indeed, we found in the UUO model that inhibition of $\beta$-catenin/TCF promotes $\beta$-catenin/Foxo in the Wnt and TGF- $\beta$ signaling pathways of bone marrow-derived macrophages (Yang et al., 2019). Importantly, redirection of $\beta$-catenin binding from TCF to Foxo resulted in reduction of inflammatory cytokines produced by bone marrow-derived macrophages, altered the fate of MMT macrophages and protected against kidney fibrosis (Yang et al., 2019).

\section{CONCLUSION}

Macrophages are master regulators of inflammation and kidney fibrosis. Monocytes and macrophages are recruited and activated in response to chemoattractants and stimuli released after kidney injury. Macrophage plasticity adds complexity to their central roles in kidney fibrosis. After kidney injury, macrophages polarize into various phenotypes in response to alteration of the microenvironment in kidney disease. M1 pro-inflammatory macrophages clear infection but also cause kidney injury; M2 anti-inflammatory macrophages contribute to resolution of inflammation and kidney repair yet cause kidney fibrosis (Tang et al., 2019). Functionally distinct macrophage phenotypes contribute to the fibro-inflammatory microenvironment by 
abundant secretion of inflammatory and anti-inflammatory cytokines, mediators of tissue repair including TGF- $\beta$, Wnt ligands, PDGF, CTGF as well as all components of RAS. Those tissue repair mediators are also key inducers of kidney fibrosis when secreted in excess and maintained at higher levels in the chronic inflammatory milieu of kidney disease. Profibrotic mediators activate a profibrotic signaling network by cross-talking among multiple signaling pathways including TGF- $\beta$, Wnts, RAS, intergin/ILK, mTOR. Importantly, multiple pro-fibrotic signaling pathways all converge at activation of $\beta$-catenin/TCF, making $\beta$-catenin/TCF a key target for prevention of kidney fibrosis. Switching $\beta$-catenin/TCF to $\beta$-catenin/Foxo redirects signaling from profibrotic to antiinflammatory and protects against kidney fibrosis. Targeting macrophages has long been proposed as a treatment for fibroinflammatory kidney diseases. However, the phenotypic plasticity

\section{REFERENCES}

Alikhan, M., and Ricardo, S. (2013). Mononuclear phagocyte system in kidney disease and repair. Nephrology 18, 81-91. doi: 10.1111/nep.12014

Anders, H. J., and Ryu, M. (2011). Renal microenvironments and macrophage phenotypes determine progression or resolution of renal inflammation and fibrosis. Kidney Int. 80, 915-925. doi: 10.1038/ki.2011.217

Arnold, L., Henry, A., Poron, F., Baba-Amer, Y., van Rooijen, N., Plonquet, A., et al. (2007). Inflammatory monocytes recruited after skeletal muscle injury switch into antiinflammatory macrophages to support myogenesis. J. Exp. Med. 204, 1057-1069. doi: 10.1084/jem.20070075

Bianchini, R., Roth-Walter, F., Ohradanova-Repic, A., Flicker, S., Hufnagl, K., Fischer, M. B., et al. (2019). IgG4 drives M2a macrophages to a regulatory M2blike phenotype: potential implication in immune tolerance. Allergy 74, 483-494. doi: $10.1111 /$ all.13635

Blumenthal, A., Ehlers, S., Lauber, J., Buer, J., Lange, C., Goldmann, T., et al. (2006). The wingless homolog WNT5A and its receptor Frizzled-5 regulate inflammatory responses of human mononuclear cells induced by microbial stimulation. Blood 108, 965-973. doi: 10.1182/blood-2005-12-5046

Braga, T., Correa-Costa, M., Silva, R., Cruz, M., Hiyane, M., da Silva, J., et al. (2018). CCR2 contributes to the recruitment of monocytes and leads to kidney inflammation and fibrosis development. Inflammopharmacology 26, 403-411. doi: 10.1007/s10787-017-0317-4

Cao, Q., Harris, D., and Wang, Y. (2015). Macrophages in kidney injury, inflammation, and fibrosis. Physiology (Bethesda, Md) 30, 183-194. doi: 10 . 1152/physiol.00046.2014

Cao, Q., Wang, C., Zheng, D., Wang, Y., Lee, V. W., Wang, Y. M., et al. (2011). IL-25 induces M2 macrophages and reduces renal injury in proteinuric kidney disease. J. Am. Soc. Nephrol. 22, 1229-1239. doi: 10.1681/asn.2010070693

Cao, Q., Wang, Y., Zheng, D., Sun, Y., Wang, C., Wang, X. M., et al. (2014). Failed renoprotection by alternatively activated bone marrow macrophages is due to a proliferation-dependent phenotype switch in vivo. Kidney Int. 85, 794-806. doi: 10.1038/ki.2013.341

Cao, Q., Wang, Y., Zheng, D., Sun, Y., Wang, Y., Lee, V. W., et al. (2010). IL-10/TGF-beta-modified macrophages induce regulatory $\mathrm{T}$ cells and protect against adriamycin nephrosis. J. Am. Soc. Nephrol. 21, 933-942. doi: 10.1681/ asn.2009060592

Chen, G., Chen, H., Wang, C., Peng, Y., Sun, L., Liu, H., et al. (2012). Rapamycin ameliorates kidney fibrosis by inhibiting the activation of mTOR signaling in interstitial macrophages and myofibroblasts. PLoS One 7:e33626. doi: 10.1371/ journal.pone.0033626

Chen, G., Lin, S., Chen, J., He, L., Dong, F., Xu, J., et al. (2011). CXCL16 recruits bone marrow-derived fibroblast precursors in renal fibrosis. J. Am. Soc. Nephrol. JASN 22, 1876-1886. doi: 10.1681/asn.2010080881

Chen, X., Wen, Z., Xu, W., and Xiong, S. (2013). Granulin exacerbates lupus nephritis via enhancing macrophage M2b polarization. PLoS One 2013, 8:e65542. and conflicting roles of M2 macrophages are major hurdles for their therapeutic application. Recently we have identified the $\beta$-catenin/TCF/Foxo axis as a key determinant of the signaling direction of multiple profibrotic pathways. Thus, targeting macrophage signaling pathway via the $\beta$-catenin/TCF/Foxo axis may provide a new promising strategy for the treatment of kidney fibrosis in chronic kidney diseases.

\section{AUTHOR CONTRIBUTIONS}

$\mathrm{JXu}$, JXie, DH, and GZ contributed to conception and design of the study. XW wrote the first draft of the manuscript. GZ, JC, JXu, DH, and JXie wrote sections of the manuscript. All authors contributed to manuscript revision, read, and approved the submitted version.

Ching, C. B., and Hansel, D. E. (2010). Expanding therapeutic targets in bladder cancer: the PI3K/Akt/mTOR pathway. Laboratory Investigat. 90, 1406-1414. doi: 10.1038/labinvest.2010.133

Chow, F., Ozols, E., Nikolic-Paterson, D., Atkins, R., and Tesch, G. (2004). Macrophages in mouse type 2 diabetic nephropathy: correlation with diabetic state and progressive renal injury. Kidney Int. 65, 116-128. doi: 10.1111/j.15231755.2004.00367.x

Chung, S., Overstreet, J. M., Li, Y., Wang, Y., Niu, A., Wang, S., et al. (2018). TGF- $\beta$ promotes fibrosis after severe acute kidney injury by enhancing renal macrophage infiltration. JCI Insight 3:e123563.

Cicha, I., Yilmaz, A., Klein, M., Raithel, D., Brigstock, D. R., Daniel, W. G., et al. (2005). Connective tissue growth factor is overexpressed in complicated atherosclerotic plaques and induces mononuclear cell chemotaxis in vitro. Arterioscler. Thromb. Vasc. Biol. 25, 1008-1013. doi: 10.1161/01.atv. $0000162173.27682 .7 \mathrm{~b}$

Conway, B. R., O’Sullivan, E. D., Cairns, C., O’Sullivan, J., Simpson, D. J., Salzano, A., et al. (2020). Kidney single-cell atlas reveals myeloid heterogeneity in progression and regression of kidney disease. J. Am. Soc. Nephrol. 31, 28332854. doi: 10.1681/asn.2020060806

Cosin-Roger, J., Ortiz-Masià, M., and Barrachina, M. (2019). Macrophages as an emerging source of Wnt ligands: relevance in mucosal integrity. Front. Immunol. 10:2297.

Das, A., Sinha, M., Datta, S., Abas, M., Chaffee, S., Sen, C. K., et al. (2015). Monocyte and macrophage plasticity in tissue repair and regeneration. Am. J. Pathol. 185, 2596-2606. doi: 10.1016/j.ajpath.2015.06.001

Eardley, K. S., Kubal, C., Zehnder, D., Quinkler, M., Lepenies, J., Savage, C. O., et al. (2008). The role of capillary density, macrophage infiltration and interstitial scarring in the pathogenesis of human chronic kidney disease. Kidney Int. 74, 495-504.

Eddy, A. (2005). Progression in chronic kidney disease. Adv. Chronic Kidney Dis. 12, 353-365. doi: 10.1053/j.ackd.2005.07.011

Eddy, A., and Neilson, E. (2006). Chronic kidney disease progression. J. Am. Soc. Nephrol. JASN 17, 2964-2966.

Eddy, A. A. (2011). Overview of the cellular and molecular basis of kidney fibrosis. Kidney Int. Suppl. 2014, 2-8. doi: 10.1038/kisup.2014.2

Eitner, F., Bücher, E., van Roeyen, C., Kunter, U., Rong, S., Seikrit, C., et al. (2008). PDGF-C is a proinflammatory cytokine that mediates renal interstitial fibrosis. J. Am. Soc. Nephrol. 19, 281-289. doi: 10.1681/asn.20070 30290

Feng, Y., Liang, Y., Zhu, X., Wang, M., Gui, Y., Lu, Q., et al. (2018a). The signaling protein Wnt5a promotes TGF $\beta 1$-mediated macrophage polarization and kidney fibrosis by inducing the transcriptional regulators Yap/Taz. J. Biol. Chem. 293, 19290-19302. doi: 10.1074/jbc.ra118.005457

Feng, Y., Ren, J., Gui, Y., Wei, W., Shu, B., Lu, Q., et al. (2018b). $\beta W n t /-$ catenin-promoted macrophage alternative activation contributes to kidney fibrosis. J. Am. Soc. Nephrol. JASN 29, 182-193. doi: 10.1681/asn.20170 40391 
Ferenbach, D. A., Ramdas, V., Spencer, N., Marson, L., Anegon, I., Hughes, J., et al. (2010). Macrophages expressing heme oxygenase-1 improve renal function in ischemia/reperfusion injury. Mol. Ther. 18, 1706-1713. doi: 10.1038/mt.20 10.100

Floege, J. (2015). Antagonism of canonical Wnt/beta-catenin signaling: taking RAS blockade to the next level? J. Am. Soc. Nephrol. 26, 3-5. doi: 10.1681/asn. 2014060567

Furuta, T., Saito, T., Ootaka, T., Soma, J., Obara, K., Abe, K., et al. (1993). The role of macrophages in diabetic glomerulosclerosis. Am. J. Kidney Dis. Offi. J. Natl. Kidney Found. 21, 480-485. doi: 10.1016/s0272-6386(12)80393-3

Guo, Q., Zhong, W., Duan, A., Sun, G., Cui, W., Zhuang, X., et al. (2019). Protective or deleterious role of $\mathrm{Wnt} / \mathrm{beta}$-catenin signaling in diabetic nephropathy: an unresolved issue. Pharmacol. Res. 144, 151-157. doi: 10.1016/j.phrs.2019. 03.022

Guo, Q., Zhu, X., Wei, R., Zhao, L., Zhang, Z., Yin, X., et al. (2020). miR-130b-3p regulates M1 macrophage polarization via targeting IRF. J. Cell. Physiol. 236, 2008-2022. doi: 10.1002/jcp.29987

Han, Y., Ma, F., Tesch, G., Manthey, C., and Nikolic-Paterson, D. (2013). Role of macrophages in the fibrotic phase of rat crescentic glomerulonephritis. Am. J. Physiol. Renal. Physiol. 304, F1043-F1053.

Hou, J., Shi, J., Chen, L., Lv, Z., Chen, X., Cao, H., et al. (2018). M2 macrophages promote myofibroblast differentiation of LR-MSCs and are associated with pulmonary fibrogenesis. Cell Commun. Sign. CCS 16:89.

Huang, W.-C., Sala-Newby, G. B., Susana, A., Johnson, J. L., and Newby, A. C. (2012). Classical macrophage activation up-regulates several matrix metalloproteinases through mitogen activated protein kinases and nuclear factor-кB. PLoS One 7:e42507. doi: 10.1371/journal.pone.0042507

Huen, S., and Cantley, L. (2015). Macrophage-mediated injury and repair after ischemic kidney injury. Pediatr. Nephrol. 30, 199-209. doi: 10.1007/s00467013-2726-y

Huen, S. C., Moeckel, G. W., and Cantley, L. G. (2013). Macrophage-specific deletion of transforming growth factor- $\beta 1$ does not prevent renal fibrosis after severe ischemia-reperfusion or obstructive injury. Am. J. Physiol. Renal. Physiol. 305, F477-F484.

Ikezumi, Y., Suzuki, T., Yamada, T., Hasegawa, H., Kaneko, U., Hara, M., et al. (2015). Alternatively activated macrophages in the pathogenesis of chronic kidney allograft injury. Pediatr. Nephrol. 30, 1007-1017. doi: 10.1007/s00467014-3023-0

Inoue, T. (2017). M1 macrophage triggered by mincle leads to a deterioration of acute kidney injury. Kidney Int. 91, 526-529. doi: 10.1016/j.kint.2016. 11.026

Jiang, Y., Wang, Y., Ma, P., An, D., Zhao, J., Liang, S., et al. (2019). Myeloid-specific targeting of Notch ameliorates murine renal fibrosis via reduced infiltration and activation of bone marrow-derived macrophage. Protein Cell 10, 196-210. doi: 10.1007/s13238-018-0527-6

Jung, M., Sola, A., Hughes, J., Kluth, D. C., Vinuesa, E., Viñas, J. L., et al. (2012). Infusion of IL-10-expressing cells protects against renal ischemia through induction of lipocalin-2. Kidney Int. 81, 969-982. doi: 10.1038/ki.20 11.446

Kadowaki, T., Yasui, Y., Takahashi, Y., Kohchi, C., Soma, G., and Inagawa, H. (2009). Comparative immunological analysis of innate immunity activation after oral administration of wheat fermented extract to teleost fish. Anticancer Res. 29, 4871-4877.

Kalish, S., Lyamina, S., Usanova, E., Manukhina, E., Larionov, N., and Malyshev, I. (2015). Macrophages reprogrammed in vitro towards the M1 phenotype and activated with LPS extend lifespan of mice with ehrlich ascites carcinoma. Med. Sci. Monitor Basic Res. 21, 226-234. doi: 10.12659/msmbr.895563

Kang, Y. S., Li, Y., Dai, C., Kiss, L. P., Wu, C., and Liu, Y. (2010). Inhibition of integrin-linked kinase blocks podocyte epithelial\&\#x2013;mesenchymal transition and ameliorates proteinuria. Kidney Int. 78, 363-373.

Karsdal, M. A., Larsen, L., Engsig, M. T., Lou, H., Ferreras, M., Lochter, A., et al. (2002). Matrix metalloproteinase-dependent activation of latent transforming growth factor-beta controls the conversion of osteoblasts into osteocytes by blocking osteoblast apoptosis. J. Biol. Chem. 277, 44061-44067. doi: 10.1074/ jbc.m207205200

Khazen, W., M'Bika, J. P., Tomkiewicz, C., Benelli, C., Chany, C., Achour, A., et al. (2005). Expression of macrophage-selective markers in human and rodent adipocytes. FEBS Lett. 579, 5631-5634. doi: 10.1016/j.febslet.2005.09.032
Kim, M. G., Kim, S. C., Ko, Y. S., Lee, H. Y., Jo, S. K., and Cho, W. (2015). The role of M2 macrophages in the progression of chronic kidney disease following acute kidney injury. PLoS One 10:e0143961. doi: 10.1371/journal.pone.0143961

Ko, G., Boo, C., Jo, S., Cho, W., and Kim, H. (2008). Macrophages contribute to the development of renal fibrosis following ischaemia/reperfusion-induced acute kidney injury. Nephrol. Dialy. Trans. Offi. Publ. Eur. Dialy. Trans. Assoc. Eur. Renal Assoc. 23, 842-852. doi: 10.1093/ndt/gfm694

Kunugi, S., Shimizu, A., Kuwahara, N., Du, X., Takahashi, M., Terasaki, Y., et al. (2011). Inhibition of matrix metalloproteinases reduces ischemia-reperfusion acute kidney injury. Laboratory Investigat. 91, 170-180. doi: 10.1038/labinvest. 2010.174

Kuppe, C., Ibrahim, M. M., Kranz, J., Zhang, X., Ziegler, S., Perales-Patón, J., et al. (2021). Decoding myofibroblast origins in human kidney fibrosis. Nature 589, 281-286.

LeBleu, V. S., Taduri, G., O’Connell, J., Teng, Y., Cooke, V. G., Woda, C., et al. (2013). Origin and function of myofibroblasts in kidney fibrosis. Nat. Med. 19, 1047-1053.

Lee, S., Huen, S., Nishio, H., Nishio, S., Lee, H., Choi, B., et al. (2011). Distinct macrophage phenotypes contribute to kidney injury and repair. J. Am. Soc. Nephrol. JASN 22, 317-326. doi: 10.1681/asn.2009060615

Li, J., Qu, X., Yao, J., Caruana, G., Ricardo, S. D., Yamamoto, Y., et al. (2010). Blockade of endothelial-mesenchymal transition by a smad3 inhibitor delays the early development of streptozotocin-induced diabetic nephropathy. Diabetes 59, 2612-2624. doi: 10.2337/db09-1631

Li, J., Ren, J., Liu, X., Jiang, L., He, W., Yuan, W., et al. (2015). Rictor/mTORC2 signaling mediates TGF $\beta 1$-induced fibroblast activation and kidney fibrosis. Kidney Int. 88, 515-527. doi: 10.1038/ki.2015.119

Li, Y., Tan, X., Dai, C., Stolz, D. B., Wang, D., and Liu, Y. (2009). Inhibition of integrin-linked kinase attenuates renal interstitial fibrosis. J. Am. Soc. Nephrol. 20, 1907-1918. doi: 10.1681/asn.2008090930

Liang, H., Zhang, Z., Yan, J., Wang, Y., Hu, Z., Mitch, W. E., et al. (2017). The IL-4 receptor $\alpha$ has a critical role in bone marrow-derived fibroblast activation and renal fibrosis. Kidney Int. 92, 1433-1443. doi: 10.1016/j.kint.2017.04.021

Lin, S., Li, B., Rao, S., Yeo, E., Hudson, T., Nowlin, B., et al. (2010). Macrophage Wnt7b is critical for kidney repair and regeneration. Proc. Natl. Acad. Sci. U.S.A. 107, 4194-4199. doi: 10.1073/pnas.0912228107

Lisi, L., Stigliano, E., Lauriola, L., Navarra, P., and Dello Russo, C. (2014). Proinflammatory-activated glioma cells induce a switch in microglial polarization and activation status, from a predominant M2b phenotype to a mixture of M1 and M2a/B polarized cells. ASN Neuro 6, 171-183.

Liu, Y. (2010). New insights into epithelial-mesenchymal transition in kidney fibrosis. J. Am. Soc. Nephrol. JASN 21, 212-222. doi: 10.1681/asn.2008121226

Lu, J., Cao, Q., Zheng, D., Sun, Y., Wang, C., Yu, X., et al. (2013). Discrete functions of M2a and M2c macrophage subsets determine their relative efficacy in treating chronic kidney disease. Kidney Int. 84, 745-755. doi: 10.1038/ki.2013.135

Lv, L., Tang, P., Li, C., You, Y., Li, J., Huang, X., et al. (2017). The pattern recognition receptor, Mincle, is essential for maintaining the M1 macrophage phenotype in acute renal inflammation. Kidney Int. 91, 587-602. doi: 10.1016/ j.kint.2016.10.020

Mantovani, A., Sica, A., Sozzani, S., Allavena, P., Vecchi, A., and Locati, M. (2004). The chemokine system in diverse forms of macrophage activation and polarization. Trends Immunol. 25, 677-686. doi: 10.1016/j.it.2004.09.015

Mao, J., Zeng, Z., Xu, Z., Li, J., Jiang, L., Fang, Y., et al. (2014). Mammalian target of rapamycin complex 1 activation in podocytes promotes cellular crescent formation. Am. J. Physiol. Renal Physiol. 307, F1023-F1032.

Meng, X., Wang, S., Huang, X., Yang, C., Xiao, J., Zhang, Y., et al. (2016b). Inflammatory macrophages can transdifferentiate into myofibroblasts during renal fibrosis. Cell Death Dis. 7:e2495. doi: 10.1038/cddis.2016.402

Meng, X. M., Nikolic-Paterson, D. J., and Lan, H. Y. (2016a). TGF- $\beta$ : the master regulator of fibrosis. Nat. Rev. Nephrol. 12, 325-338. doi: 10.1038/nrneph. 2016.48

Meng, X. M., Tang, P. M., Li, J., and Lan, H. Y. (2015). Macrophage phenotype in kidney injury and repair. Kidney Dis. 1, 138-146. doi: 10.1159/000431214

Miao, J., Liu, J., Niu, J., Zhang, Y., Shen, W., Luo, C., et al. (2019). Wnt/ $\beta$ catenin/RAS signaling mediates age-related renal fibrosis and is associated with mitochondrial dysfunction. Aging Cell 18: e13004-e.

Ng, L., Kaur, P., Bunnag, N., Suresh, J., Sung, I., Tan, Q., et al. (2019). WNT signaling in disease. Cells 8:826. 
Nie, X., Liu, H., Liu, L., Wang, Y. D., and Chen, W. D. (2020). Emerging roles of Wnt ligands in human colorectal cancer. Front. Oncol. 10:1341.

Nikolic-Paterson, D., Wang, S., and Lan, H. (2014). Macrophages promote renal fibrosis through direct and indirect mechanisms. Kidney Int. Suppl. 4, 34-38. doi: 10.1038/kisup.2014.7

Okamura, A., Rakugi, H., Ohishi, M., Yanagitani, Y., Takiuchi, S., Moriguchi, K., et al. (1999). Upregulation of renin-angiotensin system during differentiation of monocytes to macrophages. J. Hypertens 17, 537-545. doi: 10.1097/00004872199917040-00012

Palevski, D., Levin-Kotler, L. P., Kain, D., Naftali-Shani, N., Landa, N., BenMordechai, T., et al. (2017). Loss of macrophage Wnt secretion improves remodeling and function after myocardial infarction in mice. J. Am. Heart Assoc. 6:e004387.

Pan, B., Liu, G., Jiang, Z., and Zheng, D. (2015). Regulation of renal fibrosis by macrophage polarization. Cell. Physiol. Biochem. Int. J. Exp. Cell. Physiol. Biochem. Pharmacol. 35, 1062-1069. doi: 10.1159/000373932

Pang, M., Wang, H., Rao, P., Zhao, Y., Xie, J., Cao, Q., et al. (2016). Autophagy links beta-catenin and smad signaling to promote epithelial-mesenchymal transition via upregulation of integrin linked kinase. Int. J. Biochem. Cell. Biol. 76, 123-134. doi: 10.1016/j.biocel.2016.05.010

Perugorria, M., Olaizola, P., Labiano, I., Esparza-Baquer, A., Marzioni, M., Marin, J., et al. (2019). Wnt- $\beta$-catenin signalling in liver development, health and disease. Nat. Rev. Gastroenterol. Hepatol. 16, 121-136. doi: 10.1111/j.13652184.2012.00806.x

Philipp, D., Suhr, L., Wahlers, T., Choi, Y.-H., and Paunel-Görgülü, A. (2018). Preconditioning of bone marrow-derived mesenchymal stem cells highly strengthens their potential to promote IL-6-dependent M2b polarization. Stem. Cell Res. Ther. 9:286.

Pilling, D., and Gomer, R. (2012). Differentiation of circulating monocytes into fibroblast-like cells. Methods Mol. Biol. 904, 191-206. doi: 10.1007/978-161779-943-3_16

Qiao, X., Rao, P., Zhang, Y., Liu, L., Pang, M., Wang, H., et al. (2018). Redirecting TGF-beta Signaling through the beta-catenin/foxo complex prevents kidney fibrosis. J. Am. Soc. Nephrol. 29, 557-570. doi: 10.1681/asn.2016121362

Ranganathan, P. V., Jayakumar, C., and Ramesh, G. (2013). Netrin-1-treated macrophages protect the kidney against ischemia-reperfusion injury and suppress inflammation by inducing M2 polarization. Am. J. Physiol. Renal Physiol. 304, F948-F957.

Rao, P., Pang, M., Qiao, X., Yu, H., Wang, H., Yang, Y., et al. (2019). Promotion of beta-catenin/Foxo1 signaling ameliorates renal interstitial fibrosis. Lab Invest 99, 1689-1701. doi: 10.1038/s41374-019-0276-z

Rao, P., Qiao, X., Hua, W., Hu, M., Tahan, M., Chen, T., et al. (2021). Promotion of $\beta$-catenin/Foxo signaling mediates epithelial repair in kidney injury. Am. J. Pathol. 191, 993-1009. doi: 10.1016/j.ajpath.2021.03.005

Ratnayake, D., Nguyen, P. D., Rossello, F. J., Wimmer, V. C., Tan, J. L., Galvis, L. A., et al. (2021). Macrophages provide a transient muscle stem cell niche via NAMPT secretion. Nature 591, 281-287. doi: 10.1038/s41586-021-03199-7

Ricardo, S., van Goor, H., and Eddy, A. (2008). Macrophage diversity in renal injury and repair. J. Clin. Investigat. 118, 3522-3530. doi: 10.1172/jci36150

Rogers, N., Ferenbach, D., Isenberg, J., Thomson, A., and Hughes, J. (2014). Dendritic cells and macrophages in the kidney: a spectrum of good and evil. Nat. Rev. Nephrol. 10, 625-643. doi: 10.1038/nrneph.2014.170

Rosenberger, C. M., and Finlay, B. B. (2003). Phagocyte sabotage: disruption of macrophage signalling by bacterial pathogens. Nat. Rev. Mol. Cell Biol. 4, 385-396. doi: 10.1038/nrm1104

Salvador, P., Macías-Ceja, D., Gisbert-Ferrándiz, L., Hernández, C., Bernardo, D., Alós, R., et al. (2018). CD16+ macrophages mediate fibrosis in inflammatory bowel disease. J. Crohn's Colitis 12, 589-599. doi: 10.1093/ecco-jcc/jjx185

Schunk, S. J., Floege, J., Fliser, D., and Speer, T. (2021). WNT- $\beta$-catenin signalling a versatile player in kidney injury and repair. Nat. Rev. Nephrol. 17, 172-184. doi: 10.1038/s41581-020-00343-w

Shen, B., Liu, X., Fan, Y., and Qiu, J. (2014). Macrophages regulate renal fibrosis through modulating TGF $\beta$ superfamily signaling. Inflammation 37, 2076-2084. doi: 10.1007/s10753-014-9941-y

Tan, R., Zhou, D., Zhou, L., and Liu, Y. (2014). Wnt/ $\beta$-catenin signaling and kidney fibrosis. Kidney Int. Suppl. 4, 84-90. doi: 10.1038/kisup.2014.16

Tan, T. K., Zheng, G., Hsu, T. T., Lee, S. R., Zhang, J., Zhao, Y., et al. (2013). Matrix metalloproteinase- 9 of tubular and macrophage origin contributes to the pathogenesis of renal fibrosis via macrophage recruitment through osteopontin cleavage. Lab Invest 93, 434-449. doi: 10.1038/labinvest.2013.3

Tan, T. K., Zheng, G., Hsu, T. T., Wang, Y., Lee, V. W., Tian, X., et al. (2010). Macrophage matrix metalloproteinase-9 mediates epithelial-mesenchymal transition in vitro in murine renal tubular cells. Am. J. Pathol. 176, 1256-1270. doi: 10.2353/ajpath.2010.090188

Tang, L., Zhang, H., Wang, C., Li, H., Zhang, Q., and Bai, J. (2017). M2A and M2C macrophage subsets ameliorate inflammation and fibroproliferation in acute lung injury through interleukin 10 pathway. Shock 48, 119-129. doi: 10.1097/shk.0000000000000820

Tang, P. M., Nikolic-Paterson, D. J., and Lan, H. Y. (2019). Macrophages: versatile players in renal inflammation and fibrosis. Nat. Rev. Nephrol. 15, 144-158. doi: 10.1038/s41581-019-0110-2

Tseng, W., Tsai, M., Chen, N., and Tarng, D. (2020). Trichostatin a alleviates renal interstitial fibrosis through modulation of the M2 macrophage subpopulation. Int. J. Mol. Sci. 21:5966. doi: 10.3390/ijms21175966

Ulrich, C., Seibert, E., Heine, G. H., Fliser, D., and Girndt, M. (2011). Monocyte angiotensin converting enzyme expression may be associated with atherosclerosis rather than arteriosclerosis in hemodialysis patients. Clin. J. Am. Soc. Nephrol. 6, 505-511. doi: 10.2215/cjn.06870810

Urbina, P., and Singla, D. K. (2014). BMP-7 attenuates adverse cardiac remodeling mediated through M2 macrophages in prediabetic cardiomyopathy. Am. J. Physiol. Heart Circ. Physiol. 307, H762-H772.

Venturin, G., Chiku, V., Silva, K., de Almeida, B., and de Lima, V. (2016). M1 polarization and the effect of PGE on TNF- $\alpha$ production by lymph node cells from dogs with visceral leishmaniasis. Parasite Immunol. 38, 698-704. doi: 10.1111/pim. 12353

Viehmann, S. F., Böhner, A. M. C., Kurts, C., and Brähler, S. (2018). The multifaceted role of the renal mononuclear phagocyte system. Cell Immunol. 330, 97-104. doi: 10.1016/j.cellimm.2018.04.009

Wang, D., Dai, C., Li, Y., and Liu, Y. (2011). Canonical Wnt/ $\beta$-catenin signaling mediates transforming growth factor- $\beta 1$-driven podocyte injury and proteinuria. Kidney Int. 80, 1159-1169. doi: 10.1038/ki.2011.255

Wang, H., Melton, D. W., Porter, L., Sarwar, Z. U., McManus, L. M., and Shireman, P. K. (2014). Altered macrophage phenotype transition impairs skeletal muscle regeneration. Am. J. Pathol. 184, 1167-1184. doi: 10.1016/j.ajpath.2013.12.020

Wang, L. X., Zhang, S. X., Wu, H. J., Rong, X. L., and Guo, J. (2019). M2b macrophage polarization and its roles in diseases. J. Leukocyte Biol. 106, 345358. doi: 10.1002/jlb.3ru1018-378rr

Wang, M., Chen, D., Chen, L., Cao, G., Zhao, H., Liu, D., et al. (2018). Novel inhibitors of the cellular renin-angiotensin system components, poricoic acids, target Smad3 phosphorylation and $\mathrm{Wnt} / \beta$-catenin pathway against renal fibrosis. Br. J. Pharmacol. 175, 2689-2708. doi: 10.1111/bph.14333

Wang, Y., and Harris, D. C. (2011). Macrophages in renal disease. J. Am. Soc. Nephrol. 22, 21-27. doi: 10.1681/asn.2010030269

Wang, Y., Jiang, H., Pan, J., Huang, X., Wang, Y., Huang, H., et al. (2017). Macrophage-to-myofibroblast transition contributes to interstitial fibrosis in chronic renal allograft injury. J. Am. Soc. Nephrol. JASN 28, 2053-2067. doi: 10.1681/asn.2016050573

Wang, Y., Wang, Y. P., Zheng, G., Lee, V. W., Ouyang, L., Chang, D. H., et al. (2007). Ex vivo programmed macrophages ameliorate experimental chronic inflammatory renal disease. Kidney Int. 72, 290-299. doi: 10.1038/sj.ki.5002275

Wang, Y., Zhou, C., and Liu, Y. (2018). Wnt signaling in kidney development and disease. Prog. Mol. Biol. Trans. Sci. 153, 181-207. doi: 10.1016/bs.pmbts.2017. 11.019

Weichhart, T., Hengstschläger, M., and Linke, M. (2015). Regulation of innate immune cell function by mTOR. Nat. Rev. Immunol. 15, 599-614. doi: 10.1038/ nri3901

Wong, D. W. L., Yiu, W. H., Chan, K. W., Li, Y., Li, B., Lok, S. W. Y., et al. (2018). Activated renal tubular $\mathrm{Wnt} / \beta$-catenin signaling triggers renal inflammation during overload proteinuria. Kidney Int. 93, 1367-1383. doi: 10.1016/j.kint. 2017.12.017

Wu, S., Li, M., Xu, F., Li, G., Han, B., He, X., et al. (2020). Fibrinogen-like protein 2 deficiency aggravates renal fibrosis by facilitating macrophage polarization. Biomed. Pharmacother. 130:110468. doi: 10.1016/j.biopha.2020.110468

Xia, Y., Yan, J., Jin, X., Entman, M. L., and Wang, Y. (2014). The chemokine receptor CXCR6 contributes to recruitment of bone marrow-derived fibroblast precursors in renal fibrosis. Kidney Int. 86, 327-337. doi: 10.1038/ki.2014.64 
Yan, J., Zhang, Z., Yang, J., Mitch, W. E., and Wang, Y. (2015). JAK3/STAT6 stimulates bone marrow-derived fibroblast activation in renal fibrosis. J. Am. Soc. Nephrol. JASN 26, 3060-3071. doi: 10.1681/asn.2014070717

Yang, Y., Feng, X., Liu, X., Wang, Y., Hu, M., Cao, Q., et al. (2019). Fate alteration of bone marrow-derived macrophages ameliorates kidney fibrosis in murine model of unilateral ureteral obstruction. Nephrol. Dialy. Trans. Offi. Publi. Eur. Dialy. Trans. Assoc. Eur. Renal Assoc. 34, 1657-1668. doi: 10.1093/ndt/ gfy 381

Yang, Y., Nankivell, B. J., Hua, W., Rao, P., Ren, X., Yu, H., et al. (2020). Renal tubular cell binding of beta-catenin to TCF1 versus FoxO1 is associated with chronic interstitial fibrosis in transplanted kidneys. Am. J. Trans. 21, 727-739. doi: 10.1111/ajt.16287

Yu, F., Wu, L., Tan, Y., Li, L., Wang, C., Wang, W., et al. (2010). Tubulointerstitial lesions of patients with lupus nephritis classified by the 2003 international society of nephrology and renal pathology society system. Kidney Int. 77, 820-829. doi: 10.1038/ki.2010.13

Zeisberg, E. M., Potenta, S. E., Sugimoto, H., Zeisberg, M., and Kalluri, R. (2008). Fibroblasts in kidney fibrosis emerge via endothelial-to-mesenchymal transition. J. Am. Soc. Nephrol. 19, 2282-2287. doi: 10.1681/asn.20080 50513

Zhang, C., Yu, S., Zheng, B., Liu, D., Wan, F., Ma, Y., et al. (2019). miR-30c-5p reduces renal ischemia-reperfusion involving macrophage. Med. Sci. Monitor Int. Med. J. Exp. Clin. Res. 25, 4362-4369. doi: 10.12659/msm.914579

Zhang, M., Wang, X., Wang, Y., Niu, A., Wang, S., Zou, C., et al. (2017). IL4/IL-13-mediated polarization of renal macrophages/dendritic cells to an M2a phenotype is essential for recovery from acute kidney injury. Kidney Int. 91, 375-386. doi: 10.1016/j.kint.2016.08.020

Zhao, Y., Qiao, X., Wang, L., Tan, T. K., Zhao, H., Zhang, Y., et al. (2016). Matrix metalloproteinase 9 induces endothelial-mesenchymal transition via Notch activation in human kidney glomerular endothelial cells. BMC Cell Biol. $17: 21$.

Zheng, G., Lyons, J. G., Tan, T. K., Wang, Y., Hsu, T. T., Min, D., et al. (2009). Disruption of E-cadherin by matrix metalloproteinase directly mediates epithelial-mesenchymal transition downstream of transforming growth factorbeta1 in renal tubular epithelial cells. Am. J. Pathol. 175, 580-591. doi: 10.2353/ ajpath.2009.080983

Zheng, G., Zhang, J., Zhao, H., Wang, H., Pang, M., Qiao, X., et al. (2016). alpha3 integrin of cell-cell contact mediates kidney fibrosis by integrin-linked kinase in proximal tubular E-cadherin deficient mice. Am. J. Pathol. 186, 1847-1860. doi: 10.1016/j.ajpath.2016.03.015

Zhou, B., Liu, Y., Kahn, M., Ann, D. K., Han, A., Wang, H., et al. (2012). Interactions between beta-catenin and transforming growth factorbeta signaling pathways mediate epithelial-mesenchymal transition and are dependent on the transcriptional co-activator cAMP-response element-binding protein (CREB)-binding protein (CBP). J. Biol. Chem. 287, 7026-7038. doi: 10.1074/jbc.m111.276311

Zhou, G., Li, J., Zeng, T., Yang, P., and Li, A. (2020). The regulation effect of WNT-RAS signaling in hypothalamic paraventricular nucleus on renal fibrosis. J. Nephrol. 33, 289-297. doi: 10.1007/s40620-019-00637-8

Conflict of Interest: The authors declare that the research was conducted in the absence of any commercial or financial relationships that could be construed as a potential conflict of interest.

Publisher's Note: All claims expressed in this article are solely those of the authors and do not necessarily represent those of their affiliated organizations, or those of the publisher, the editors and the reviewers. Any product that may be evaluated in this article, or claim that may be made by its manufacturer, is not guaranteed or endorsed by the publisher.

Copyright (c) 2021 Wang, Chen, Xu, Xie, Harris and Zheng. This is an open-access article distributed under the terms of the Creative Commons Attribution License (CC BY). The use, distribution or reproduction in other forums is permitted, provided the original author(s) and the copyright owner(s) are credited and that the original publication in this journal is cited, in accordance with accepted academic practice. No use, distribution or reproduction is permitted which does not comply with these terms. 